\title{
Pairing Students of Different Proficiency Levels in Saudi Secondary Schools
}

Khawlah Fahad Aljouei*

Department of Curriculum and Instruction, College of Education, King Saud University, Riyadh, Saudi Arabia

\begin{abstract}
The purpose of the present study is to examine the effectiveness of pair work on students of different proficiency levels. Twenty Saudi female students, attending secondary school, have participated in the study Ten of them were high proficiency level $(\mathrm{H})$ and ten were low proficiency level $(\mathrm{L})$. Each participant was engaged in a speaking task twice; once with a partner of the same level and once with a partner of the opposite level. All tasks were audio recorded and transcribed. Results of the amount of the LREs and language practice revealed that, heterogeneous pairing is effective in the multi-level classrooms.
\end{abstract}

Keywords: Proficiency level; Pair-work; Language related episodes (LREs)

\section{Introduction}

Studies in the field of communicative second language learning have made clear evidence supporting the thought that language is best leaned as students interact. When it is compared with teacher centered classrooms, students have better opportunities of language practice as they work in pairs [1]. Students also get higher academic results when they work cooperatively [2]. Concerning the anxiety level, students are fewer anxieties when they are speaking to only one partner, and yet the goal in getting speaking practice is being attained [3]. There is, however, less practical research on the effect of proficiency-pairing on students' speaking practices in the English as a foreign language EFL classrooms. The present study reveals a research on the effectiveness of proficiency pairing on Saudi students' language related episodes RLE' occurrence and amount of language production within a paired speaking task. The three types of investigated proficiency pairing are: Low proficiency-High proficiency (L-H), High Proficiency-High proficiency $(\mathrm{H}-\mathrm{H})$ and Low Proficiency-Low proficiency (L-L). Interest in this specific issue came from my experience in teaching EFL large classrooms which contain differences of proficiency levels among the students.

\section{Literature Review}

In the field of second language learning and teaching, researchers have been extensively searching for the effectiveness of the cooperative learning that includes group and pair work activities. Cooperative learning reflects the concepts of the sociocultural theory by Vygotsky which describes the leaning process as social. Employing Vygotsky's theory found that when children talk in groups they help each other with vocabulary and focus only on the task goal which made them less stressful [4]. He has exposed 10-12 years old children to a TV cartoon film and asked them to retell the story once individually and another time within a group. Yost findings show that people are more likely to produce language when they are engaged with others [4]. The ESL learners' perceptions of the small group and pair work was determined by Polly which showed that, group work and pair work is useful and the cooperative work is the key to the participation. Polly has confirmed that the perception of the language learners plays an important role in their willingness to participate and when learners observe group or pair work as a positive way of learning they will interact positively.

Baleghizadeh and Farhesh have examined the impact of pair work on the motivation of English as a second language for learners [5]. The authors examine pair-work not only from the students' attitudes but also from the teachers' perspectives through interviewing teachers to observe their attitudes towards the use of pair work in EFL classrooms. The results of the study show a significant difference between the paired group and the individual group which indicates that pair work enhances the motivation of the learners.

To observe the effectiveness of cooperative leaning in the development of the students' grammatical proficiency Alghamdi and Gillies has formed a study resulted to a significant difference in the posttest scores between the experimental group (which has studied through cooperative learning) and the control group (which has studied by a traditional method), the experimental group retained higher scores [6]. Alghamdi and Gillies referred this difference in the scores to the cooperative discussions students apply when doing tasks in groups and to the opportunity offered to weak students to ask their able peers [6].

The pairing of mixed proficiency level classrooms was debated in recent years. Watanabe has observed the outcomes of the interactive dialogues between the second language learners of different proficiency levels [7]. The data of his study was collected through comparing composition writings of four Japanese participants once they are paired with a higher level pairs and other time when they are paired with pairs of lower levels. Individual compositions were compared with the students' post writing tasks. The students' discussions while performing the tasks were audio-recorded. Watanabe found that the core participants achieved higher post-test scores when they are engaged in an interactive sitting and they produced more language when paired with a higher level peers [7]. Moreover, Davis has conducted a study to examine the impact of the interlocutor on the students' oral assessment. He divided 20 students into two groups of high and low proficiency levels and given them a collection of pictures

${ }^{*}$ Corresponding author: Khawlah Fahad Aljouei, Department of Curriculum and Instruction, College of Education, King Saud University, Riyadh, Saudi Arabia, Tel+ 966 14670888; E-mail: 436203694@student.ksu.edu.sa

Received January 06, 2018; Accepted January 19, 2018; Published January 24 2018

Citation: Aljouei KF (2018) Pairing Students of Different Proficiency Levels in Saudi Secondary Schools. Arts Social Sci J 9: 329. doi: 10.4172/2151-6200.1000329

Copyright: @ 2018 Aljouei KF. This is an open-access article distributed under the terms of the Creative Commons Attribution License, which permits unrestricted use, distribution, and reproduction in any medium, provided the original author and source are credited. 
for an oral discussion [8]. Davis Found that, the high-level students were not affected when paired with high or low leveled pairs but the students with low proficiency levels produced more words when paired with high-level students. Likewise, storch and Aldosary has found that, pair work can motivate students to use the language within their peers and for the kind of pairing they found that pairing students depend on the kind of activity [9]. They examined the effectiveness of pairing students in a Saudi college ESL class to determine how to pair students in a mixed proficiency ESL class. Moreover, Watanabe and Swain have selected four core participants and paired them once with higher-level students and another time with lower-level students [7]. They found that students gain higher scores when they are paired regardless of the level of proficiency.

The language related episodes LREs were examined in several studies to show the quantity and quality of these episodes and how pair and group work are a key factor of stimulating these episodes. LREs are defined by Swain and Lapkin (as cited by Watanabe and Swain) as any segments of the speech where learners question the language they produced [10]. Storch and Aldosari found that pairing students of different proficiency levels has a clear effect in the number of LREs produced. According to (Watanabe) the high pairs produced more frequent LREs when the are paired with high peers. It has been found that the noticing task stimulated more LREs than the writing task (Watanabe and Swain) [9]

Finally, being exposed to these studies which investigate the effectiveness of the group and pair work in the English as a second language classrooms, I have come to the idea of expanding the applications of such cooperative methods more often in my own classrooms. As a teacher of mixed proficiency level classrooms, I have examined the effectiveness of pairing students of different proficiency levels in terms of the LREs and the quantity of the L2 produced.

\section{The Study}

\section{Participants}

The present study includes 20 participants from a public secondary school in Riyadh, Saudi Arabia. Participants are female students at the age of 17 to 19, attending their second and third secondary school years. Regarding the proficiency level, participants were chosen and classified by their teacher. Ten of the participants were classified as high level of English and 10 students as low English level. Each participant was engaged in the speaking tasks in two terms, once paired with a partner of the same level and the other time with a partner of the opposite level. Specifically, the $\mathrm{H}$ was paired with $\mathrm{H}(\mathrm{H}-\mathrm{H})$, the $\mathrm{L}$ was paired was paired with $\mathrm{L}(\mathrm{L}-\mathrm{L})$ and the $\mathrm{H}$ was paired with $\mathrm{L}(\mathrm{H}-\mathrm{H})$.

\section{Speaking tasks}

The speaking tasks were taken from MM Publication books which are adapted by the Saudi curriculum to be taught in secondary schools. Four speaking tasks were used in this study (Appendix II), two were used for the first sessions in which the students were classified as $(\mathrm{H}$ $\mathrm{H})$ and $(\mathrm{L}-\mathrm{L})$ and two were used in the second sessions where students were classified as $(\mathrm{H}-\mathrm{L})$. All activities are structured interaction in which the students are engaged in conversations discussing pictures and ideas. The first task inquires the students to discuss the idea of learning English as a second language in Saudi Arabia. The task provides questions to be discussed, such as providing the best ways of learning a second language and comparing the learning at the person's own pace with learning in a classroom atmosphere. The second task provides the students with four pictures of different heroes with given questions to be discussed. Both tasks include keywords and pictures for more clarification. In the second speaking sessions students of different English proficiency levels (H-L) were mixed and given a different speaking task. In the first prompt students were presented with two pictures of people applying scientific experiments and were asked to discuss these pictures. The second prompt presents two pictures of two men having different jobs (a tour guide and a receptionist) and students were asked to discuss the advantages and disadvantages of each job. Audio recordings were started as the students were given the task sheets, so students were recorded since they were reading instructions and questions.

\section{Data Collection}

The interactive sessions between the pairs were completed in a duration of approximately three to fifteen minutes. During the task performance, twenty interactive task sessions between the pairs were audio recorded and then transcribed as text. These recordings and transcriptions are the main source of data in the present study. The collected data was used to measure the quantity of the Language related episodes (LREs) and the amount of L2 used by the participants.

\section{Data Analysis}

\section{Language related episodes (LREs)}

Language related episodes (LREs) are parts of students' interactions in which they either talk about or ask about their language or their partners' when preforming a L2 task [10]. The transcription of the pair talk was coded for the LREs. The frequency of the language related episodes was counted in all the interactive sessions. Three types of interactive pairings was taken into consideration in terms of quantity, they are $(\mathrm{H}-\mathrm{H}),(\mathrm{H}-\mathrm{L})$ and $(\mathrm{L}-\mathrm{L})$. The concern of this study was on lexis-oriented LREs and form-oriented LREs. The lexis-oriented are when students question or ask about the word choice or word meaning and the form-oriented deals with grammatical forms. In excerpt 2 there is an example of the lexis-Oriented LREs where Shahad (the low proficiency level participant) questions Sara (the high level) about a way of saying the Arabic word kahraba \{electricity in English and Sara provides the English equivalent of the Arabic word.

Excerpt 2: LO-LREs

129. Sara: ...What other experiments did you get?

130. Shahad: Other, another?..... this... yeah we put it the salt in the water and the ... aaa wish yane kahraba? \{How can I say electricity\}

131. Sara: electricity

132. Shahad: yeah and its aa when put it in.. the...

In excerpt 3 another example of lexis-oriented LREs can be seen between Raghad and shahad (L-L). This example shows an incorrect resolution of the question in the turns (27-29) where Shahad asks Raghad about the meaning of the word "common" and Raghad gives her an incorrect equivalent.

\section{Excerpt 3: LO-LREs}

27. Shahad: (reading) "what is the most common" ...what's the mean common?

28. Raghed:...... al waseal al taleamiah $\{$ the educational aids\}

29. Shahad: " common ways to learn foreign language".

In excerpt 8 two different proficiency level (H-L) students were 
discussing pictures related to science. The transcribed discourse of this excerpt shows an example of the form-oriented LREs in the turns 3135. In this turn Hanan (H) corrects Amera's (L) sentence "not easy" implicitly by just rephrasing the correct grammatical way of saying the sentence "it's not easy".

\section{Excerpts 8: FO-LREs}

31. Hannan: why isn't it interesting for you are just mixing some aa.. things and ...some colors

32. Amera: not aa.. easy.

33. Hanan: yes it's not easy. yeah me to I think so it is not easy.

34. Amera: I don't the aaa

\section{Quantity of the L2 produced}

For the quantity of the L2 words produces by the participants all words were counted for each student in her two turns (the Arabic words were excluded). That is, the amount of $\mathrm{L} 2$ words produced by the learners of low proficiency level was counted twice, the first time was counted when they were paired with the high level learners and the second time was counted when they were paired with the low level learners. Using SPSS (statistical analysis software) the mean of each pairing was dignified and then compared with the mean of other pairings. Moreover, the mean of the number of the high level leaners was counted once when they were paired with learners of the low level and the other time was counted when they were paired with other learners of high level.

\section{Results}

\section{Quantity of the L2 produced}

Do low proficiency level students students produce more L2 when they are paired with students of their level or of a higher level? In the present study the amount of L2 produced by the Low level students appears to be influenced by the interlocutor. Statistics of this study shows that, when L level participants are paired with L level they produce less amount of L2 and when they are paired with $\mathrm{H}$ they produce more amount of word but the difference of word amount is not significant.

Table 1 shows that the mean number of the L2 spoken words for the $\mathrm{H}$ as they are paired with $\mathrm{H}$ is 370.3 and 499.5 when they are paired with L. Moreover, the mean of word count of the L when they are paired with $\mathrm{L}$ is 212.3 words and 259.5 if they are paired with high level. This means that that when $(\mathrm{H}-\mathrm{L})$ are paired, the $\mathrm{H}$ level students speak approximately $59 \%$ of the words and the L proficiency produce $41 \%$ of the L 2 word. These averages and findings are shown in the bar graph below (Figure 1)

\section{Language related episodes (LREs)}

Through the coding of the transcribed audio recordings a number of LREs was observed. The study shows that when the high level students are paired with same level in the speaking tasks little LREs

\begin{tabular}{|c|c|c|c|c|}
\hline $\begin{array}{c}\text { Student } \\
\text { Proficiency }\end{array}$ & $\begin{array}{c}\text { Partner's } \\
\text { proficiency }\end{array}$ & Mean & Std. Deviation & $\begin{array}{c}\text { Std. Error } \\
\text { Mean }\end{array}$ \\
\hline High $(n=10)$ & High & 370.3000 & 309.30857 & 97.81196 \\
\hline High $(n=10)$ & Low & 499.5000 & 455.85408 & 144.15372 \\
\hline Low $(n=10)$ & Low & 212.7000 & 201.77989 & 63.80840 \\
\hline Low $(n=10)$ & High & 259.5000 & 218.20900 & 69.00374 \\
\hline
\end{tabular}

Table 1: Quantity of L2 Produced (number of words spoken).

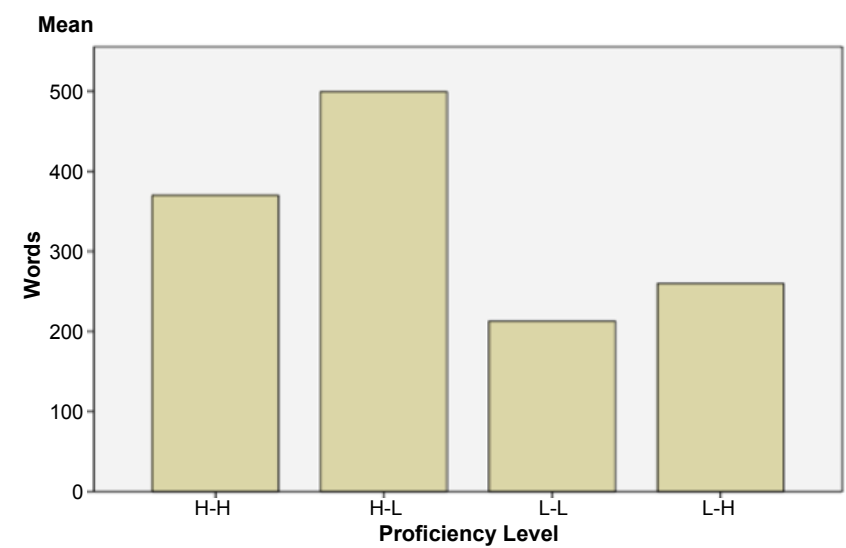

Figure 1: The average of L2 word count in different proficiency levels.

\begin{tabular}{|c|c|c|c|}
\hline & H-H & H-L & L-L \\
\hline $\mathrm{N}$ & 5 & 10 & 5 \\
\hline Mean & 0.2000 & 2.5000 & 1.4000 \\
\hline \multicolumn{2}{|c|}{ Table 2: Quantity of L-LREs. } \\
\hline
\end{tabular}

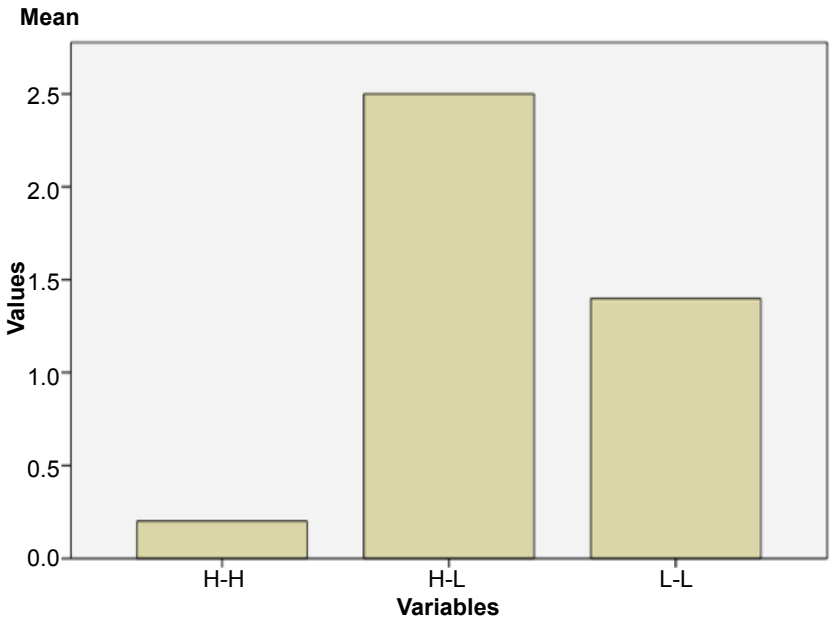

Figure 2: The difference of the amount of LREs that happen in the pairing of different proficiency level students.

accrues. During five speaking tasks of $(\mathrm{H}-\mathrm{H})$ pairing only one LREs has accrued. On the other hand, when they were paired with low proficiency students more amount of LREs accrues. During ten speaking tasks of (H-L) pairing twenty-eight LREs was counted. Also, when the low proficiency students are paired with the low level some LREs accrued but its not always resolved correctly. Seven LREs was counted as the (L-L) was paired in five speaking tasks.

Table 2 shows that, the average quantity of the LREs of 5 pairs $(\mathrm{H}-$ $\mathrm{H})$ is 0.2 . The different proficiency pairing $(\mathrm{H}-\mathrm{L})$ showed the largest average number which is 2.5 per 10 pairs. For the (L-L) the mean of LREs is 1.4. The bar graph (Figure 1) below shows the difference of the amount of LREs that happen in the pairing of different proficiency level students (Figure 2).

\section{Discussion}

The purpose of the study was to study the possible kind of proficiency pairing in a mixed proficiency level classroom. The results 
showed that, the proficiency level of the interlocutor has an effect on the students' L2 amount produced and also on the production of the LREs. According to the present study, L students speak more when they are paired with partners of the same level. This finding is consistent with previous studies [7,9], which reveals that students produce more L2 word when they are paired with a higher level, and contradicts with (storch and Aldosary [9] who found that low proficiency students produced less L2 words when they are paired with a high proficiency. Regarding the amount of L2 talk of the low proficiency students, this study suggests that students of different proficiency are best to be paired heterogeneously. That is, the L proficiency are best to be paired with $\mathrm{H}$ proficiency to enhance their speaking abilities. As for the $\mathrm{H}$ proficiency students Davis has found that, they are not effected when paired with any proficiency level, the presents study contradicts [8]. Davis showing that the $\mathrm{H}$ students produce more language when they are paired with the L proficiency [8].

Concerning the LREs, the present study has examined the quantity of the LREs of different proficiency level pairs. Results revealed that, when $\mathrm{H}$ proficiency level students are paired with $\mathrm{H}$ proficiency, they produce little or no LREs in the speaking tasks. These results, contradicts with (Watanabe) who found that the $\mathrm{H}$ proficiency produce more LREs when they are paired with $\mathrm{H}$ partners [7]. According to the current study, the largest amount LREs accurses as the $\mathrm{H}$ proficiency was paired with low proficiency.

\section{Conclusion}

After conducting the study on pairing students of different proficiency level, I found that pairing students has an effect on the amount of language production and feedback. Students who work with high proficiency level partners have greater chances of language accuracy and use. Also, low proficiency students are more likely to have correct feedback from their high proficiency partners. Therefore, the current study determines that, teachers who have large classes of multi-level of English proficiency, are advised to pair their students heterogeneously. Concerning the students of high proficiency level, further research is required for better understanding of the effects of heterogeneous pairing on their language learning.

\section{References}

1. Kirkpatrick R, Ghaemi H (2011) Beyond the communicative approach in language teaching. Modern Journal of Language Teaching Methods 1: 143-149.

2. Johnson DW, Johnson RT (2002) Learning Together and Alone: Overview and Meta, Äêanalysis Asia Pacific Journal of Education 22: 95-105.

3. Young DJ (1992) Language Anxiety from the Foreign Language Specialist's Perspective: Interviews with Krashen Omaggio Hadley Terrell and Rardin Foreign Language Annals 25: 157-172.

4. Yost KA (2001) A sociocultural study of young second-language learners and group work (Order No 1406805) Available from Pro Quest Dissertations Theses Global (219989293).

5. Baleghizadeh S, Farhesh S (2014) Impact of Pair Work on EFL Learners Motivation MEXTESOL Journal 38: 3.

6. Alghamdi R, Gillies R (2013) The impact of cooperative learning in comparison to traditional learning (small groups) on EFL learners' outcomes when learning English as a foreign language Asian Social Science 9: 19-27.

7. Watanabe $Y$, Swain M (2007) Effects of proficiency differences and patterns of pair interaction on second language learning: Collaborative dialogue between adult ESL learners Language Teaching Research 11: 121-142.

8. Davis $L$ (2009) The influence of interlocutor proficiency in a paired ora assessment Language Testing 26: 367-396.

9. Storch N, Aldosari A (2012) Pairing learners in pair-work activity Language Teaching Research 17: 31-48.

10. Swain M, Lapkin S (2001) Focus on form through collaborative dialogue: Exploring task effects. In: Bygate M, Skehan P, Swain M (eds.) Researching pedagogic tasks: Second anguage learning teaching and testing Harlow: Longman, pp: 99-118. 